\title{
Haemorrhage from the upper alimentary tract
}

\author{
J. N. MacCAIG, S. L. STRANGE, AND T. ST. M. NORRIS \\ From the Gastro-Enterological Unit, Whittington Hospital, London
}

EDITORIAL SYNOPSIS This is a study based on 587 patients with acute bleeding from the upper alimentary tract. After excluding 17 with carcinoma of the stomach and 11 with oesophageal varices, the overall mortality was $7.7 \%$. No fewer than $51 \%$ of patients were over 60 years of age. Emergency surgery was needed in $14 \cdot 3 \%$. From follow-up studies it is concluded that elective gastrectomy should be performed in patients with gastric ulcer in whom bleeding ceases after admission.

\section{MATERIAL}

During the four-year period 1957-60 there were 618 admissions to this unit for the treatment of haemorrhage from the upper alimentary tract. Some patients were admitted on more than one occasion and the total number of patients involved was 587 (Table I). Of this total, $11(1.9 \%)$ were found to be bleeding from oesophageal varices and $17(2.9 \%)$ from carcinoma of the stomach. Of the remaining 559 patients who are the subject of more detailed study, $285(51 \%)$ were over the age of 60 and $232(42 \%)$ were women. The age distribution of the cases is shown in Figure 1.

\section{TABLE I}

SOURCE OF HAEMORRHAGE

$\begin{array}{lrr}\text { Duodenal ulcer } & 210 & (35.6 \%) \\ \text { Gastric ulcer } & 155 & (26.5 \%) \\ \text { Acute group } & 157 & (26.8 \%) \\ \text { Post-operative group } & 21 & (3.6 \%) \\ \text { Incompletely investigated group } & 16 & (2.7 \%) \\ \quad \text { Total } & 559 & \\ \text { Carcinoma of stomach } & 17 & (2.9 \%) \\ \text { Oesophageal varices } & 11 & (1.9 \%) \\ \quad \text { Grand total } & 587 & \end{array}$

DUODENAL ULCER There were 210 patients in the series found to have a duodenal ulcer: $88(42 \%)$ were over the age of 60 and $47(22.4 \%)$ were women. There were 10 deaths $(4.8 \%)$, the mortality rising to $10 \%$ over the age of 60 years. Emergency surgery was undertaken in 25 cases $(11.9 \%)$, of which five were women, and there were three deaths.

GASTRIC ULCER There were 155 patients bleeding from a gastric ulcer and of these $98(63.5 \%)$ were over the age of 60 , and $77(49.5 \%)$ were women. There were 26 deaths $(16.8 \%)$, the mortality rising to $24.5 \%$ over the age of 60 years. Emergency surgery was undertaken in 51 cases $(33 \%)$, of which 23 were women, and there were nine deaths.

One patient was admitted with abdominal pain and haematemesis. He had a chronic gastric ulcer and cirrhosis with thrombosis of the mesenteric vein and gangrene of the small gut. The gangrenous gut was resected and the patient made a satisfactory recovery. This patient was readmitted 18 months later with ascites, which did not respond to medical treatment, and he died 12 days later following a

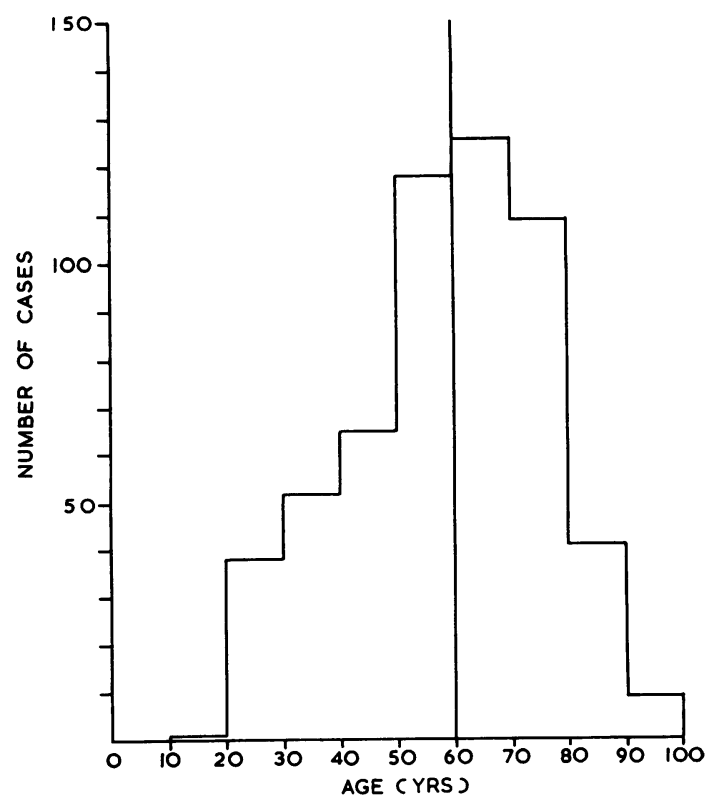

FIG. 1. Age distribution of cases. 
haematemesis. At necropsy he had an eroded artery in the floor of a gastric ulcer of the lesser curve, measuring $6 \times 4 \mathrm{~cm}$. The liver showed severe 'hobnail' fibrosis with regeneration nodules and a hepatoma involving most of the right lobe. The hepatoma had extended into and occluded the hepatic veins. The portal vein contained organizing ante-mortem thrombus throughout its length.

ACUTE GROUP This group includes all patients in whom barium meal examination, emergency operation, or necropsy failed to reveal evidence of peptic ulceration, carcinoma, or oesophageal varices. There were 157 patients in this group with $79(50.2 \%)$ over the age of 60 and $90(57 \cdot 3 \%)$ women. There were four deaths, all in patients over 60 , giving a mortality of $2.5 \%$ for the whole group $(5 \%$ over the age of 60$)$. Five patients $(3.2 \%)$ had emergency surgery.

Seven patients were found to be bleeding from gastritis and of these the diagnosis was made at gastroscopy in one patient, at emergency operation in five, and at necropsy in one.

A number of other lesions were demonstrated in this group and the relation of these lesions to the haemorrhage is uncertain. These lesions included duodenal diverticulum (9), oesophageal diverticulum (1), jejunal and Meckel's diverticula (1), oesophageal reflux only (1), and hiatus hernia (14). (An hiatus hernia was demonstrated in a further 14 patients, 10 of whom also had a duodenal ulcer and four had a gastric ulcer.) Eight patients gave a history of taking salicylates before the haemorrhage.

Only in one patient in this group was the haemorrhage the main factor in causing death. In the other three the fall in haemoglobin was very small and the causes of death in these three cases were chronic myeloid leukaemia, acute myocardial infarction, and bronchopneumonia, respectively.

POST-OPERATIVE GROUP Most of these patients had had operations many years before admission here with haemorrhage and the operations were done at a number of different hospitals. The types of operation performed and the lesion present at the time of these operations are shown in Table II. The total number of patients in this group is 21 . There were no deaths

\section{TABLE II}

TYPES OF OPERATION ORIGINALLY PERFORMED IN POST-OPERATIVE GROUP

\begin{tabular}{lc} 
Operation & No. of Cases \\
\hline Billroth I gastrectomy for gastric ulcer & 4 \\
Billroth I gastrectomy for duodenal ulcer & 1 \\
Polya gastrectomy for duodenal ulcer & 6 \\
Gastro-enterostomy for duodenal ulcer & 9 \\
Gastro-enterostomy and vagotomy for duodenal ulcer & 1
\end{tabular}

and none required emergency surgery. Elective surgery was carried out for stomal ulcer in 10 cases; six patients with previous gastro-enterostomy for duodenal ulcer had dismantling of the gastroenterostomy and Polya gastrectomy, three patients with previous Polya gastrectomy had vagotomy, and one patient with previous gastro-enterostomy and vagotomy had a Polya gastrectomy. In the other 11 patients in this group no ulcer could be demonstrated on barium meal or gastroscopy and further surgery was not undertaken.

INCOMPLETELY INVESTIGATED GROUP There were 10 women and six men who were incompletely investigated. Barium meals were not done in four of them because of pregnancy, in one who discharged himself prematurely, in two because of severe deformity due to rheumatoid arthritis, in one patient who was disabled by hemiplegia, and in three patients over 80 and four over 90 who were too frail or ill to stand this examination. One woman, aged 51, died of a stroke two days after admission with haematemesis. There were three deaths in the group and permission for necropsy was refused in all.

INCREASED BLEEDING TENDENCY Three patients had an increased bleeding tendency. Acute gastritis was responsible for the bleeding in one with chronic myeloid leukaemia, while a duodenal ulcer was the source in one with idiopathic thrombocytopenia and in another with hereditary telangiectasia.

TREATMENT

Our routine of treatment of these patients follows the generally accepted methods of giving liberal oral fluids and soft foods, adequate sedation, and transfusion.

TRANSFUSION It is our general policy to transfuse patients freely. We consider that patients are better able to survive repeated haemorrhage if the haemoglobin is maintained at a reasonable level and we took as our guide the level of $70 \%$ (Haldane). Indications for transfusions were, therefore, first the

TABLE II I

PROPORTION OF PATIENTS REQUIRING TRANSFUSION RELATED TO DIAGNOSIS

Cause of Haemorrhage No. Requiring Transfusion

\begin{tabular}{lrl}
\hline Duodenal ulcer & 103 & $(48 \%)$ \\
Gastric ulcer & 101 & $(64 \cdot 7 \%)$ \\
Acute group & 72 & $(45 \cdot 8 \%)$ \\
Post-operative group & 9 & $(42 \cdot 8 \%)$
\end{tabular}


treatment of shock and secondly the maintenance of a haemoglobin level of $70 \%$. Transfusion was most often required in patients bleeding from gastric ulcer (Table III).

EMERGENCY SURGERY Emergency surgery was undertaken in 80 patients $(14.3 \%)$ with 12 deaths, a mortality of $15 \%$. Over the same period there were 58 elective operations following haemorrhage without any deaths. Emergency operation was required more often for bleeding from gastric ulcer than for bleeding from duodenal ulcer (Table IV).

\section{TABLE IV}

NUMBERS OF PATIENTS REQUIRING EMERGENCY SURGERY Cause of Bleeding Under Age 60 Age 60 and Over Total

No. $\%$ No. $\%$ No. $\%$

\begin{tabular}{llllllllll}
\hline Duodenal ulcer & 11 & $(1)^{1}$ & 9 & 14 & (2) & 15.9 & 25 & (3) & 11.9
\end{tabular}

$\begin{array}{llllllllll}\text { Gastric ulcer } & 17 & \text { (1) } & 29.8 & 34 & \text { (8) } & 35 & 51 & \text { (9) } & 33\end{array}$

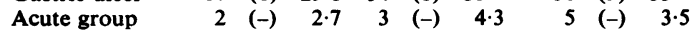

${ }^{1}$ Deaths in parenthesis

The main indications for emergency surgery were persistent and recurrent haemorrhage. Perforation and pyloric stenosis each precipitated operation on two occasions. On six occasions no ulcer was demonstrated at laparotomy and gastrotomy and in four of these partial gastrectomy was performed. In three of these four the presence of gastritis was confirmed histologically. In one of the two in whom gastrectomy was not performed (a man aged 43) bleeding persisted after operation and the patient died. At necropsy a shallow gastric ulcer was found in the lower half of the stomach with an eroded artery in its base. The other five recovered without further bleeding.

ELECTIVE SURGERY Elective surgery was undertaken in 58 patients $(11 \%)$. The incidence of elective surgery in the various diagnostic groups is shown in Table $\mathrm{V}$.

\section{TABLE V}

NUMBERS OF PATIENTS TREATED BY ELECTIVE SURGERY IN

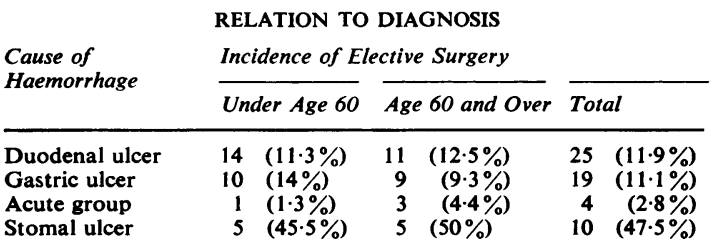

\section{RESULTS OF TREATMENT}

RECURRENT HAEMORRHAGE We use the term 'recurrent haemexrhage' to mean a further episode of haemorrhage some months or years after the completion of treatment for a first haemorrhage. Many of our patients have not been followed for a full year after their first haemorrhage and may have gone elsewhere with a subsequent haemorrhage. Recurrent haemorrhage rates are therefore incomplete. However, the incidence of recurrent haemorrhage at present is shown in Table Vl and for the reasons already mentioned these are minimum figures and the true incidence will be higher. The

\section{TABLE VI}

PROPORTION OF PATIENTS HAVING A SECOND HAEMORRHAGE ONE, FIVE, AND 35 YEARS AFTER THE FIRST

\begin{tabular}{lllllll}
$\begin{array}{l}\text { Source of } \\
\text { Haemorrhage }\end{array}$ & \multicolumn{4}{l}{$\begin{array}{l}\text { Interval between First and Second } \\
\text { Haemorrhage }\end{array}$} \\
\cline { 2 - 7 } & $0-1$ Year & $0-5$ Years & $0-35$ Years \\
\hline Duodenal ulcer & 27 & $(14.6 \%)$ & 56 & $(30.3 \%)$ & 75 & $(40.6 \%)$ \\
Gastric ulcer & 11 & $(12.5 \%)$ & 28 & $(31.8 \%)$ & 41 & $(46.6 \%)$ \\
Acute group & 13 & $(9 \%)$ & 25 & $(17.4 \%)$ & 27 & $(18.8 \%)$
\end{tabular}

recurrence rates do not vary significantly with age and are similar in the gastric and duodenal ulcer groups. As might be expected, the overall recurrence rates are a little lower than in other reported series (Donaldson, Handy, and Papper, 1958; Gardner and Baronofsky, 1959; Ward-McQuaid, Pease, McEwen Smith, and Twort, 1960). Figures quoted are the number of patients surviving a first haemorrhage without surgery and having a second haemorrhage within one, five, and 35 years. It will be seen that over $40 \%$ of patients bleeding from a demonstrable duodenal or gastric ulcer have had a second haemorrhage.

DEATHS There were 43 deaths in the series related to haemorrhage. Two other patients, who were admitted to hospital with haematemesis, died of other conditions while in the ward. One of these died of extensive recurrence of a chromophobe

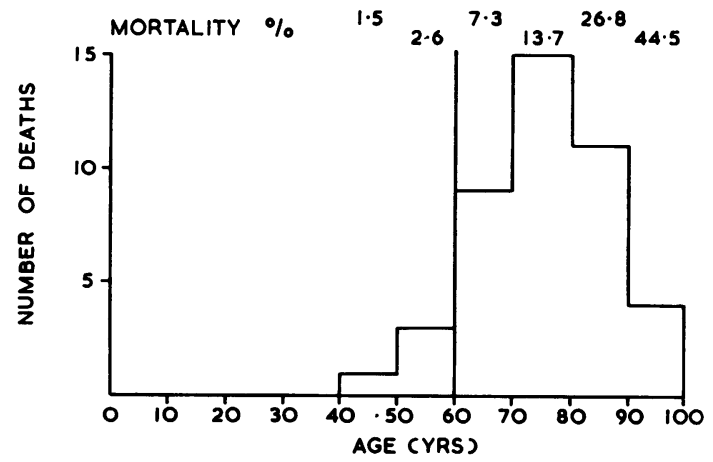

FIG. 2. Mortality by age groups. 
adenoma of the pituitary and the other from carcinomatosis, the primary being in the bronchus. The overall mortality is, therefore, $7 \cdot 7 \%$, and the age distribution of the deaths is shown in Figure 2. As in other series (Coghill and Willocx, 1960), elderly men fare worse than elderly women. The mortalities over the age of 60 are shown in Table VII.

\section{TABLE VII}

PERCENTAGE MORTALITY IN PATIENTS OVER 60 WITH DUODENAL AND GASTRIC ULCER

\begin{tabular}{lcc} 
Source of Haemorrhage & Men & Women \\
\hline Duodenal ulcer & $11 \cdot 2$ & $7 \cdot 7$ \\
Gastric ulcer & $28 \cdot 3$ & 23.6 \\
Total & $15 \cdot 3$ & 12.8
\end{tabular}

MORTALITY OF FIRST AND SUBSEQUENT HAEMORRHAGE The mortality from second haemorrhage was less than that for the first ones (Table VIII) but still very much higher in the gastric ulcer group than in the other two. Deaths from third haemorrhage are among such small groups that the figures are not significant.

TABLE VIII

MORTALITY OF FIRST AND SUBSEQUENT HAEMORRHAGES

\begin{tabular}{|c|c|c|c|c|c|}
\hline \multirow[t]{2}{*}{ Source of Haemorrhage } & \multicolumn{2}{|c|}{ First } & \multicolumn{2}{|c|}{ Second } & Third \\
\hline & & $\begin{array}{l}\text { aths } \\
\text { ortality }(\%)\end{array}$ & & $\begin{array}{l}\text { aths } \\
\text { ortality (\%) }\end{array}$ & $\begin{array}{l}\text { Deaths } \\
\text { Mortality (\%) }\end{array}$ \\
\hline $\begin{array}{l}\text { Duode } \\
\text { Gastric }\end{array}$ & $\begin{array}{r}8 \\
21\end{array}$ & $\begin{array}{r}3.8 \\
13.6\end{array}$ & 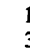 & $\begin{array}{l}1 \cdot 7 \\
7 \cdot 3\end{array}$ & $\begin{array}{rr}1 & 3.2 \\
1 & 11.8\end{array}$ \\
\hline Acute group & 4 & $2 \cdot 5$ & - & - & $-\quad-$ \\
\hline
\end{tabular}

DEATHS FOLLOWING EMERGENCY SURGERY Twelve patients died after surgery had been undertaken; one, aged 83, had stomal hold-up after a Billroth I gastrectomy and after a second operation to convert this to a Polya gastrectomy the anastomosis broke down. One patient, aged 79 , had a giant gastric ulcer $(6 \mathrm{~cm}$. diameter) which lay in close proximity to the diaphragm; repeated haemorrhage made emergency surgery her only hope of survival but chronic bronchitis and her general debility led to her death after operation. One patient died of haemorrhage from a chronic gastric ulcer not visualized at laparotomy and gastrotomy (already mentioned). Three patients died of pulmonary emboli; two from acute myocardial infarctions; one from pneumonia due to resistant staphylococcus; one from leakage from the duodenal stump after Polya gastrectomy; one had splenectomy alone in view of his thrombocytopenia (platelets 36,000) and at necropsy was found to have died of haemorrhage from a duodenal ulcer and one died of secondary haemorrhage from the gastro-duodenal artery 20 days after emergency gastrectomy for a duodenal ulcer.

DEATHS FOLLOWING MEDICAL TREATMENT Thirtyone patients died without having surgery. One patient persistently refused operation and died of perforation of a gastric ulcer. Twelve patients died of haemorrhage; one died within minutes of her arrival on the ward before transfusion could be given; another died on the day of admission despite transfusion, for a gastric ulcer had eroded the splenic artery leading to profuse haemorrhage; another patient died of massive haemorrhage from a gastric ulcer while being transfused before operation; one patient had chronic myeloid leukaemia and died of profuse haemorrhage from acute gastritis despite transfusion. Eight patients were aged 77 to 93, and in view of their frail general condition surgery was not considered. Despite transfusion in all but one, they died of haemorrhage. In retrospect we feel that more active transfusion and early emergency surgery might have saved some of them. We now believe that old age should not deny any patient the hope that surgery alone might offer. The cause of death in the other 18 patients was: myocardial infarction (7), bronchopneumonia (6), cerebrovascular accident (3), cor pulmonale (1), and left ventricular failure (1).

\section{DISCUSSION}

This series is of relatively elderly patients, $51 \%$ being aged 60 or over. The rapid increase in mortality above this age, due to the increasing incidence of cardiovascular, cerebrovascular, and pulmonary diseases, has been stressed before (Avery Jones, 1956). The mortality of $7.7 \%$ appears average for this elderly group (Table IX). The comparable series described by Large (1960) has the low mortality of $5.9 \%$.

As in most other series the prognosis is much worse for haemorrhage from gastric than duodenal ulcers and the mortalities in the 'acute group' and post-operative group are small. The mortality of haemorrhage from gastric ulcer is more than twice that from duodenal ulcer, even allowing for the greater proportion of elderly patients in the former group (Fig. 3). Moreover, the transfusion rates are higher and the emergency surgery rate is nearly three times as high. These two criteria may reasonably be said to indicate the greater tendency of haemorrhage from gastric ulcers to be both severe and persistent. In this group we have again found that haemorrhage from large gastric ulcers is likely to persist. Patients known to have a large gastric ulcer 
TABLE IX

COMPARISON WITH SOME OTHER REPORTED SERIES

\begin{tabular}{lcccc} 
Series & $\begin{array}{l}\text { Percentage of Cases } \\
\text { Over Age } 60\end{array}$ & $\begin{array}{l}\text { Percentage } \\
\text { Emergency } \\
\text { Operations }\end{array}$ & $\begin{array}{l}\text { Percentage } \\
\text { Mortality in Series }\end{array}$ & $\begin{array}{l}\text { No. of Patients in } \\
\text { Series }\end{array}$ \\
\hline Cates (1959) & 33 & $13 \cdot 5$ & $5 \cdot 4$ & 300 \\
Gaunt (1960) & $34 \cdot 5$ & $4 \cdot 5$ & $4 \cdot 5$ & 400 \\
Ward-McQuaid et al. (1960) & 38 & $24 \cdot 5$ & $6 \cdot 25$ & 1,764 \\
Avery Jones (1956) & 40 & 10 & $7 \cdot 9$ & 377 \\
Fraenkel and Truelove (1955) & 42 & $14 \cdot 1$ & $5 \cdot 6$ & 534 \\
Avery Jones (1961) & $43 \cdot 5$ & $10 \cdot 5$ & $9 \cdot 1$ & \\
Waterson (1956) & 45 & 9 & $5 \cdot 9$ & 589 \\
Large (1960) & $50 \cdot 9$ & $19 \cdot 9$ & $7 \cdot 7$ & 559
\end{tabular}

as the source of haemorrhage should have emergency surgery (Strange, 1959).

From our figures it appears that about half of those patients surviving their first haemorrhage from a gastric ulcer without operation will have a further haemorrhage and the mortality of this second haemorrhage is likely to be about $7 \%$. Thus, $3 \%$ or more of those surviving their first haemor-

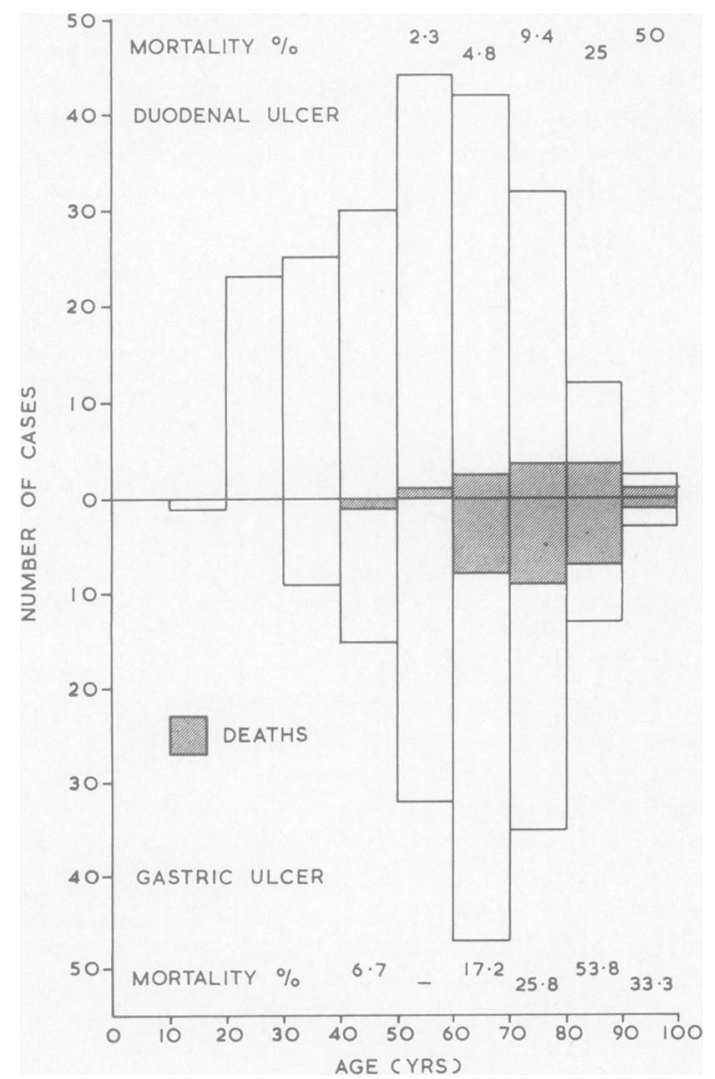

FIG. 3. Comparative mortality for gastric and duodenal ulcer cases by age groups. rhage from gastric ulcer are likely to die from a second haemorrhage. This is greater than the mortality of elective gastrectomy in experienced hands. We have no figures for the incidence of haemorrhage after gastrectomy for gastric ulcer, but it appears to be very low and such recurrence is unlikely to be serious. We therefore feel that elective gastrectomy should be seriously considered in patients over the age of 60 who have their first haemorrhage from a demonstrated gastric ulcer.

Nine patients died of acute myocardial infarction complicating gastro-intestinal haemorrhage and two of these had emergency surgery. It is now routine practice in this unit to have an electrocardiogram done on all patients over the age of 50 admitted with haemorrhage in an effort to avoid operating in the presence of acute myocardial infarction. We have also found a pre-operative electrocardiogram of value as a base-line in the event of post-operative collapse following either emergency or elective surgery.

In view of the very low incidence of active peptic ulceration during pregnancy, it was a surprise to find four pregnant women in this series. The diagnosis of peptic ulcer in all was presumptive only because none attended for radiological investigation after parturition. One of them, however, had a history of peptic ulcer and had a second haemorrhage requiring transfusion six weeks after the first. Since completion of this series we have had a case of a pregnant woman bleeding from a chronic duodenal ulcer who required emergency gastrectomy with satisfactory outcome for mother and child (Strange, 1962).

\section{REFERENCES}

Cates, J. E. (1959). A review of 300 patients with haematemesis or melaena. Brit. med. J., 1, 206-211.

Coghill, N. F., and Willocx, R. G. (1960). Factors in the prognosis of bleeding chronic gastric and duodenal ulcers. Quart. J. med., 29, 575-596.

Donaldson, R. M., Handy, J., and Papper, S. (1958). Five year follow-up study of patients with bleeding duodenal ulcer with and without surgery. New Engl. J. Med., 259, 201-207.

Fraenkel, G. J., and Truelove, S. C. (1955). Haematemesis, with special reference to peptic ulcer. Brit. med. J., 1, 999-1002. 
Gardner, B., and Baronofsky, I. D. (1959). The massively bleeding duodenal ulcer with special reference to crater. Surgery, 45, 389-402.

Gaunt, R. T. (1960). Quoted by Ward-McQuaid et al. (1960).

Jones, F. Avery (1956). Haematemeses and melaena with special reference to causation and to the factors influencing the mortality from bleeding peptic ulcers. Gastroenterology, 30, 166-190.

- (1961). Abdominal operations, edited by R. Maingot, 4th ed., p. 286. Lewis, London.
Large, J. M. (1960). Gastro-duodenal haemorrhage as a surgical emergency. Brit. med. J., 1, 932-935.

Strange, S. L. (1959). Giant innocent gastric ulcer. Its behaviour and treatment. Brit. med. J., 1, 476-480.

(1962). Massive haemorrhage from duodenal ulcer in pregnancy. Proc. roy. Soc. Med., 55, 798-799.

Ward-McQuaid, J. N., Pease, J. C., McEwen Smith, A., and Twort, R. J. (1960). Surgery in bleeding peptic ulcers. Gut, 1, 258-265.

Waterson, A. P. (1956). Haematemesis and melaena in Cambridge. Amer. J. dig. Dis., 1, 193-205. 